\title{
Acute Renal Insufficiency after Radiofrequency of Renal Tumor
}

\author{
Francualdo Barreto, Marcos F. Dall'Oglio, Miguel Srougi
}

Division of Urology, School of Medicine, University of Sao Paulo, USP, Sao Paulo, SP, Brazil

\begin{abstract}
Recent advances in techniques of imaging and ablation have led to the application of several minimally invasive modalities, such as radiofrequency ablation (RFA) with a success rate varying from 79 to $96 \%$ and a serious complication rate of 1 to $4 \%$ in the treatment of small renal tumors.

The authors report on the case of a 67-year-old patient with a radiofrequency ablation complication, stenosis of the ureteropelvic junction in one kidney, and analyze the results of this modality for the treatment of renal tumors.
\end{abstract}

Key words: Kidney neoplasms; catheter ablation; renal insufficiency

Int Braz. J Urol. 2007; 33: 679-82

\section{INTRODUCTION}

Traditionally, the treatment of renal tumors included radical or partial nephrectomy. Minimally invasive treatment modalities such as cryotherapy and radiofrequency ablation (RFA) by percutaneous approach have been used in the treatment of carcinoma of the renal cells, offering some advantages, such as shorter convalescence, lesser pain, lower costs and better esthetic effect, if compared to conventional surgery (2).

The authors report on the case of a 67-yearold patient with a radiofrequency ablation complication, stenosis of the ureteropelvic junction (UPJ), in one kidney, and analyze the results of this modality for the treatment of renal tumors.

\section{CASE REPORT}

A 67-year-old man had undergone a radical left nephrectomy 5 years before due to a grade- 1,8 $\mathrm{cm}$, carcinoma of the renal cells. During a routine consultation, using computed tomography (CT) a solid lesion was located in the lower medial region, in the remaining kidney (Figure-1). Biochemical assessment presented urea at $38 \mathrm{mg} / \mathrm{dL}$ and creatinine at $0.9 \mathrm{mg} /$ $\mathrm{dL}$. The patient was submitted to percutaneous RFA in February 2003, after which acute renal insufficiency developed (creatinine at $7.0 \mathrm{mg} / \mathrm{dL}$ ), requiring urgent nephrostomy after fifteen days. Imaging confirmed the presence of stenosis of the UPJ (Figure-2), the patient having been submitted to endopielotomy with an unsuccessful attempt to place a double iota catheter. 


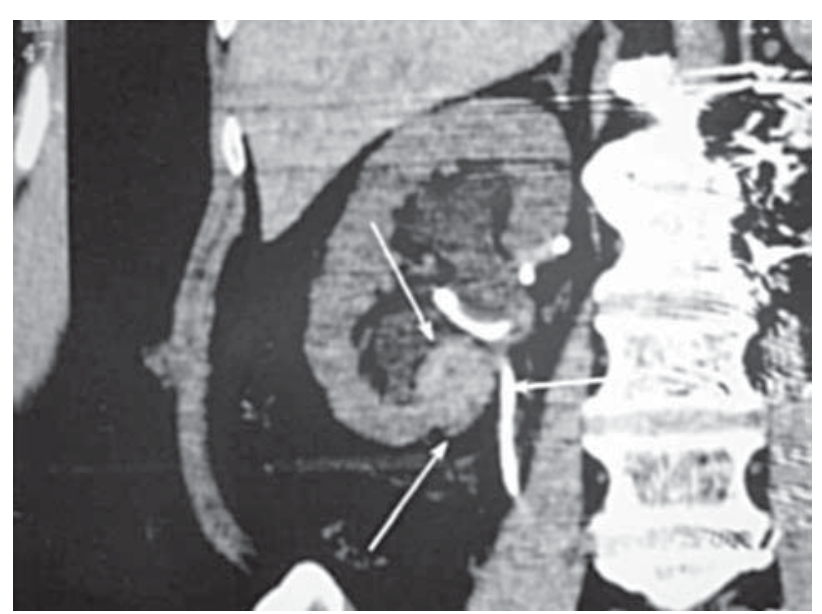

Figure 1-Computed tomography demonstrating renal nodule of $3.5 \mathrm{~cm}$ in remaining kidney.

The patient sought out our institution to verify the therapeutic possibilities. Open pyeloplasty was recommended, followed by the enucleation of the renal nodule. The pathological examination revealed a necrotic area with the formation of abscesses, fibrosis and a granulomatose reaction of the foreign-body type, with no evidence of a viable tumor (Figure-3). The patient progressed well (Figure-4), currently having a creatinine level of $1.9 \mathrm{mg} / \mathrm{dL}$.

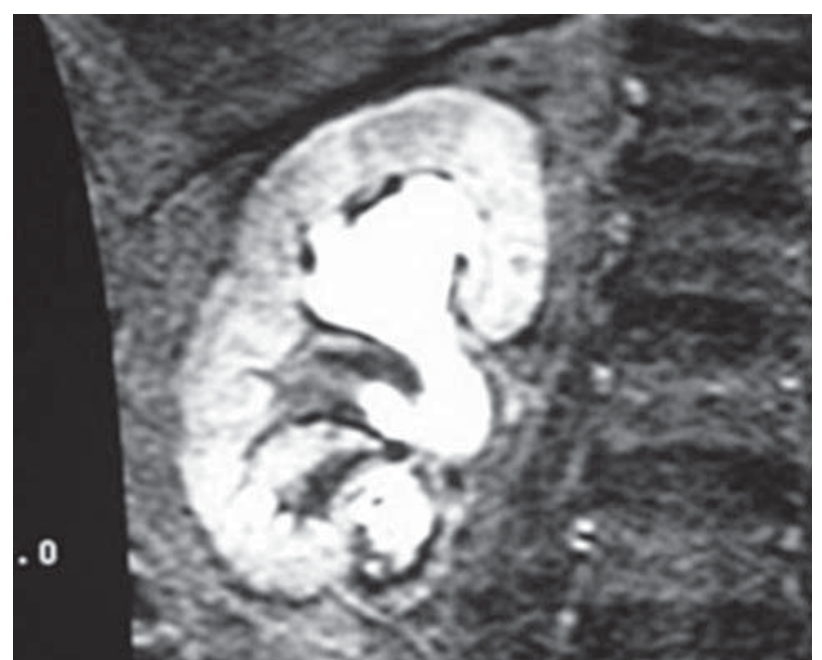

Figure 2 - Stenosis of ureteropelvic junction by magnetic resonance.

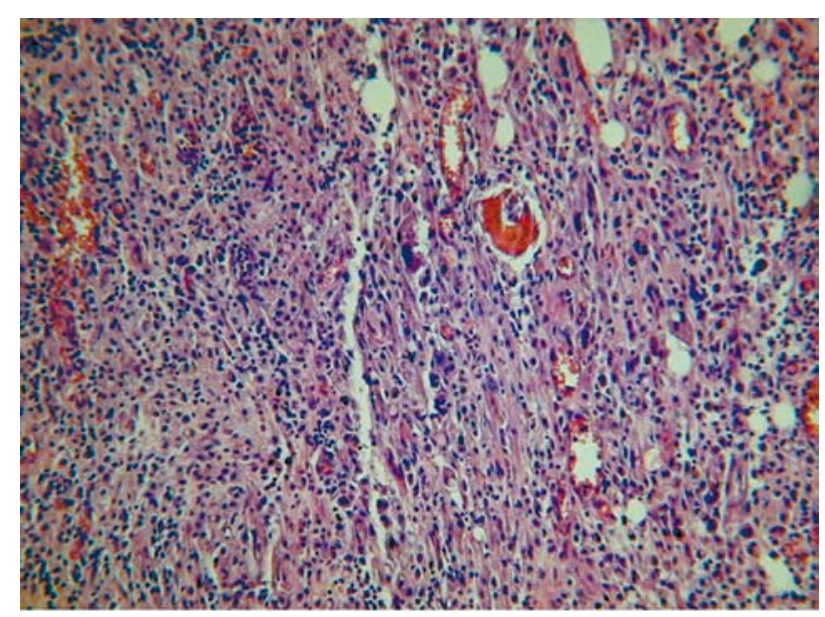

Figure 3-Necrotic area, fibrosis and granulomatose reaction of the foreign-body type. Absence of viable residual neoplasia (HE X400).

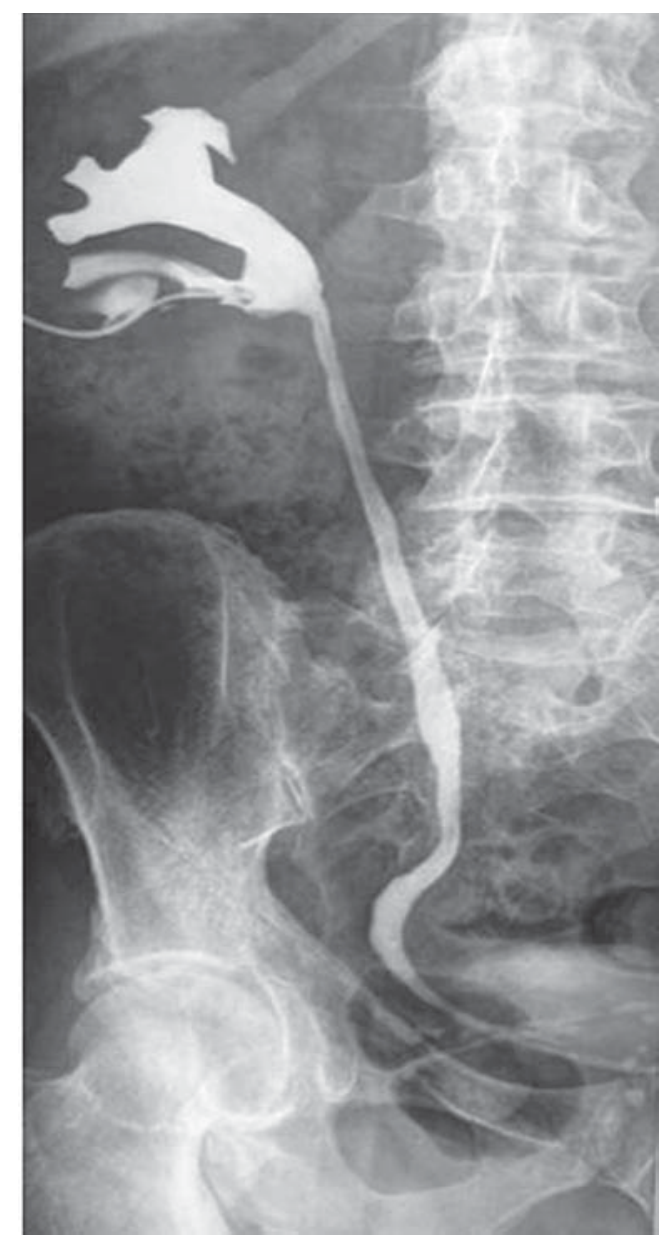

Figure 4-Antegrade pyelogram demonstrating evident ureteropelvic junction. 


\section{COMMENTS}

RFA has been used recently as a new treatment option for small renal tumors with a success rate of 79 to $96 \%$ of the cases $(2,3)$, the incidence of serious complications, such as intestinal lesion, cutaneous fistula, urethral stenosis and pneumothorax, occurs in 1 to $4 \%(1,2)$.

Radiofrequency ablation (RFA) is to be recommended for the treatment of renal tumors of less than $3 \mathrm{~cm}$, which have given signs of growth during the period of one year. Surgical approach may vary either by means of percutaneous puncture (3) or by laparoscopy (2). The principle of RFA involves heating to high temperatures $(<70$ degrees $\mathrm{C})$ thus provoking necrosis of coagulation and cell death $(2,3)$. The criteria of inclusion for RFA are solid lesions $<3$ $\mathrm{cm}$, which have been growing over the previous year, creatinine below $2.0 \mathrm{mg} / \mathrm{dL}$ and 24-hour creatinine clearance greater than $60 \mathrm{~mL} / \mathrm{min}(2,3)$. The position of the tumor (posterior, lateral or medial) has not been considered among the exclusion criteria, although the proximity of the colon, duodenum or of important vessels is a limiting factor for this technique (1-3). The most frequent complications arising from RFA are hematuria (4 to $8 \%$ ), proteinuria (16\%), low back pain $(16 \%)$ and perirenal hematoma (4\%), and these are treated conservatively $(2,3)$.

The criterion of cure is confirmed by the absence of the visualization of contrast $(<10 \mathrm{UH})$ on tomography, with a success rate of 79 to $96 \%(2,3)$.

Stenosis of the UPJ may occur in $4 \%$ of the cases, being presented after two months (2). According to some authors, the position of the tumor does not constitute a criterion of exclusion, but rather a limitation of the applicability of the technique (2,3). According to Hwang et al., open pyeloplasty is the best way to deal with this complication (2), particularly in the reported case, as we are dealing with a sole kidney in a rather delicate situation. An alternative technique in the case of an extensive lesion would be the interposition of the loop ileal.

The RFA of small renal tumors, whether by percutaneous approach or laparoscopy, still requires further study for the assessment of the method's efficiency and safety. If the long-term results are favorable, then RFA could be an attractive treatment option for solid renal lesions.

\section{CONFLICT OF INTEREST}

None declared.

\section{REFERENCES}

1. Rhim H, Dodd GD 3rd, Chintapalli KN, Wood BJ, Dupuy DE, Hvizda JL, Sewell PE, Goldberg SN: Radiofrequency thermal ablation of abdominal tumors: lessons learned from complications. Radiographics. 2004; 24: 41-52.

2. Hwang JJ, Walther MM, Pautler SE, Coleman JA, Hvizda J, Peterson J, et al.: Radio frequency ablation of small renal tumors:: intermediate results. J Urol. 2004; 171: 1814-8.

3. Pavlovich CP, Walther MM, Choyke PL, Pautler SE, Chang R, Linehan WM, et al.: Percutaneous radio frequency ablation of small renal tumors: initial results. $\mathrm{J}$ Urol. 2002; 167: 10-5.

\author{
Correspondence address: \\ Dr. Françualdo Barreto \\ Rua Vitoriano Palhares, 218, Apto 1201 \\ Recife, PE, 50710-190, Brazil \\ Fax: + 5581 3226-1184 \\ E-mail: fjbarreto@terra.com.br
}




\section{EDITORIAL COMMENT}

The management of small renal tumors is changing over the years to a nephron-sparing surgery. Of the various ablation techniques, radiofrequency ablation and cryotherapy are being increasingly applied clinically (1). They can be performed both laparoscopically or percutaneously using a combination of probes and imaging techniques for focusing and monitoring the therapy. Noninvasive tumor ablation by high-intensity focused ultrasound, and other techniques, are still on experimental stage.

Although the initial outcomes of cryoablation and radiofrequency ablation are encouraging, long-term data are necessary to confirm their efficacy. Early reports of the technique's effectiveness are promising (2). Dr Inderbir Gill from the Cleveland Clinic published 51 patients undergoing cryotherapy for a unilateral, sporadic renal tumor with a 3-year cancer spe- cific survival of $98 \%$. There was no open conversion, kidney loss, urinary fistula, dialysis requirement, or perirenal or port site recurrence in any patient.

These ablative techniques should be reserved for carefully selected patients, the data should be prospectively studied and the results should be compared to the standard treatment, open or laparoscopic partial nephrectomy.

\section{REFERENCES}

1. Aron M, Gill IS: Renal tumor ablation. Curr Opin Urol. 2005; 15: 298-305.

2. Gill IS, Remer EM, Hasan WA, Strzempkowski B, Spaliviero M, Steinberg AP, et al.: Renal cryoablation: outcome at 3 years. J Urol. 2005; 173: 1903-7.

\section{Dr. Mauricio Rubinstein} Section of Urology State of Rio de Janeiro Federal University UNIRIO

Rio de Janeiro, RJ, Brazil E-mail: mrubins@attglobal.net 